\title{
Processo de redemocratização do Brasil após 1964 com ênfase na Lei de Anistia e sua importância para o ensino da história
}

Brazil's redemocratization process after 1964 with emphasis on the Amnesty Law and its importance for the teaching of history.

Silas Fernandes Cunha Junior *

Eleno Marques de Araújo *

\begin{abstract}
Resumo
O presente estudo objetiva verificar qual a relevância para democracia brasileira da Lei $n^{\circ} 6.683$ - Lei da Anistia - e investigar que aspectos podem ser considerados positivos com o advento dessa Lei e de que forma tornou possível a apresentação de resultados sociais produzidos por ela na consolidação da democracia, visando o ensino-aprendizagem. Foi utilizada revisão bibliográfica aprofundada. Conclui-se que a compreensão desse olhar diferenciado, poderá ampliar o reconhecimento da lei na história como aspecto educativo e transformador.
\end{abstract}

\section{Palavras-chave}

Redemocratização Brasileira. Lei de Anistia. Crise Política no Brasil após 1964. Ensino da História na ditadura.

\begin{abstract}
This study aims to verify the relevance for Brazilian democracy of Law 6,683 - Amnesty Law - and investigate what aspects can be considered positive with the advent of this Law and how it made possible the presentation of the social results produced by it in consolidation of democracy, with the aim of teaching and learning. An in-depth bibliographic review was used. It can be concluded that the understanding of this differentiated aspect can broaden the recognition of the law in history as an educational and transformative aspect.
\end{abstract}

\section{Keywords}

Brazilian Redemocratization. Amnesty law. Political Crisis in Brazil after 1964. Teaching of History in Dictatorship..

\footnotetext{
* Silas Fernandes Cunha Junior, Graduando do curso de Medicina na instituição Centro Universitário de Mineiros- UNIFIMES e Graduando do curso de história pela instituição Centro Universitário Claretiano. E-mail: silasfjunior@gmail.com.

* Doutor em ciências da religião pela PUC-GO. Pesquisador no CNPQ pelo GP-NEPEM UNIFIMES e Membro do GEFOPI-UEG, Diretor de pesquisa e professor adjunto na UNIFIMES.
} 


\section{Introdução}

Após lentos processos de transição para a democracia, o general João Batista Figueiredo, trouxe de volta os primeiros brasileiros exilados no exterior pela Ditadura Militar, amparado pela Lei $n^{0}$ 6.683/79. Os movimentos sociais desempenharam importante papel na organização da resistência aos atos institucionais e na luta pela anistia no Brasil formado através de comitês que reuniam a sociedade civil e de direitos humanos em defesa de políticas de memória, reparação, justiça e verdade - e de parcela de organismos governamentais como a Comissão de Anistia do Ministério da Justiça e a Comissão Especial de Mortos e Desaparecidos da Secretaria Especial de Direitos Humanos da Presidência da República. Diante desses movimentos, o governo encaminhou ao Congresso o seu projeto, em junho de 1979. O projeto governista atendia apenas parte do apelo nacional, porque excluía os condenados por terrorismo e favorecia os militares, incluindo os responsáveis pelas práticas de tortura.

Nesse sentido, esse artigo tem como premissa investigar os aspectos considerados positivos com o advento dessa Lei e de que forma tornou possível a apresentação de resultados sociais produzidos por ela na consolidação da democracia, bem como, qual sua importância para o ensino da história, visando o ensino-aprendizagem. Desta forma, apresentam-se os conceitos do que foi a Lei de Anistia, análise e aplicabilidade da lei, e também, aspectos e relevâncias.

Com relação à redemocratização brasileira apresenta-se história e conceito, bem como, anistia e a crise política no Brasil após 1964. E no que se refere ao ensino apresentase a redemocratização brasileira e sua importância para o ensino de história, discorrendo sobre um breve histórico das transformações ocorridas no ensino de história durante o Regime Militar no Brasil.

A intenção é de sistematizar informações sobre esta temática, fazendo uma breve análise a partir de algumas teorias através de artigos especializados, conceitos e concepções da Lei.

A orientação indicativa, consoante o texto da redemocratização brasileira com ênfase na Lei da Anistia é a filosofia que permeia o direcionamento das normas, práticas sociais, elementos fáticos dos casos concretos, e assim por diante, tem o propósito de permitir as interpretações que é a função primordial de resolver conflitos de interesses. Através da história social, política e econômica baseadas nas legislações vigentes permitese ver o quanto é importante conhecer essas transformações.

O presente estudo se justifica por ceder melhor compreensão ao observar que a Lei de Anistia foi formulada de maneira a perdoar agressores e vítimas de forma que os últimos se desse por satisfeitos em readquirir direitos políticos, enquanto que os ditadores, ou seja, os torturadores ficassem sem pagar pelos atos praticados em defesa da 
continuidade de ações antidemocráticas, negando-se a possibilidade de analisar as violações de direitos ocorridas durante o regime.

A razão da escolha do tema se prende ao fato de se poder averiguar a aplicabilidade da Lei da Anistia como instrumento do processo de redemocratização brasileira para que se analise todo esse processo.

Para a realização do estudo foram utilizados materiais relevantes ao tema, coletados de livros técnicos e publicações de órgãos internacionais e nacionais, revistas e artigos de ordem científica, a fim de possibilitar aprofundamento literário e formulação de conclusão pessoal sobre os questionamentos gerais propostos no estudo.

Como metodologia foi utilizada revisão bibliográfica aprofundada de assuntos pertinentes ao tema, incluindo análise crítica e interpretação literária. Todo material abordado foi selecionado, de forma que houvesse uma separação criteriosa, a fim de se obter qualidade e quantatividade nas informações e dados.

\section{O que é a Lei da Anistia}

Promulgada em 28 de Agosto de 1979, foi responsável por possibilitar a anistia a presos e perseguidos políticos.

\section{Conceito}

A Lei da anistia é a denominação popular da Lei $\mathrm{n}^{\circ} 6.683$, promulgada pelo presidente Figueiredo em 28 de agosto de 1979, após uma ampla mobilização social, ainda durante o regime militar. A luta pela anistia aos presos e perseguidos políticos foi protagonizada por estudantes, jornalistas e políticos de oposição. Foi o ato legislativo mais importante e que marcou o fim da ditadura militar no Brasil. Portal Brasil, (2014).

Em junho de 1979, o governo João Batista Figueiredo encaminhou ao Congresso Nacional o seu projeto que atendia apenas parte dos interesses sociais porque excluía os condenados por atentados terroristas e assassinados, segundo o seu art. $1^{\mathrm{o}}$, favorecendo também os militares e os responsáveis pelas práticas de tortura.

A lei estabelece que:

Art. $1^{\circ}$ É concedida anistia a todos quantos, no período compreendido entre 2 de setembro de 1961 e 15 de agosto de 1979, cometeram crimes políticos ou conexos com estes, crimes eleitorais, aos que tiveram seus direitos políticos suspensos e aos servidores da Administração Direta e Indireta, de Fundações vinculadas ao Poder Público, aos servidores dos Poderes Legislativo e Judiciário, aos militares e aos dirigentes e representantes 
sindicais, punidos com fundamento em Atos Institucionais e Complementares (Vetado). ( Lei $\mathrm{n}^{\mathrm{o}} 6.683 / 79$ ).

Diante de tal prerrogativa ela foi questionada por diversos segmentos da sociedade por ter beneficiado torturadores e violadores de direitos humanos. Porém, a AGU reiterou "o entendimento de que a Lei da Anistia abrange os atos praticados por agentes do Estado em virtude do caráter amplo, geral e irrestrito do benefício" (JORNAL O POVO, 2009).

A luta pela anistia, nos termos históricos, é uma espécie de síntese política da resistência no Brasil. Ainda assim, é comum o erro de análise em valer-se do significado etimológico e tradicional da palavra "anistia" para menosprezar seu conteúdo histórico substancial. Faz-se fundamental lembrar que a ideia da Anistia foi concebida como um instrumento para reconhecer o direito dos cidadãos terem opiniões e defendê-las para que a democracia prevaleça, cabendo a todos zelar para que esses direitos não sejam violados.

As várias interpretações e discussões tiveram como finalidade atender todos os interesses para que cumprisse a missão pelo qual foi proposta, tornando uma lei objetiva e que amparasse a todos na questão da justiça e dos direitos humanos (SILVA, 2010).

\section{Análise e aplicabilidade da Lei}

Nesse tópico discutiremos a análise e a aplicabilidade da lei que concebeu a anistia aos exilados.

\section{Análise}

Com o golpe militar o Brasil teve governos autoritários e milhares de cidadãos foram vítimas de ameaça, exílio, tortura e morte pelo regime, surgindo a necessidade de mudanças. Neste cenário, se precisava de instrumentos legais que possibilitassem uma relativa conciliação entre o passado ditatorial e o presente. Assim, foram editadas as chamadas Leis de Anistia, tanto no Brasil como em outros países, que concederam perdão aos crimes do período, afetando sua punibilidade e beneficiando tanto os opositores do regime - presos políticos, exilados, etc.- quanto os seus partidários.

O direito à reparação no Brasil, dando ênfase a declaração de anistiado é um gesto oficial e legal de pedidos de desculpas pelo Estado em que reconhece ter perseguido politicamente a um cidadão ou uma cidadã e que promoveu contra eles atos de exceção, causando-lhe prejuízos morais e materiais.

Cumpre registrar que algumas linhas de pensamentos apregoam que a anistia representou a limitação social e afirmação da ideologia que dominava o poderio político, 
porém a luta pela Anistia abriu caminhos para o Brasil alcançar a democracia, uma vez que a consolidação do Estado democrático exigiu o resgate do espírito da Anistia e reconheceu o direito do povo brasileiro de se indignar contra as injustiças sociais, a corrupção e o combate à impunidade diante das violações constantes dos direitos humanos.

Segundo Cunha, dá para perceber que ocorreram avanços comparados com a ordem vigente anterior a sua promulgação. Porém, esses avanços representaram o fruto de um pensar da época que conseguiu manter uma linearidade histórica no país, mas não representou necessariamente uma “expressão de justiça” (CUNHA, 2010, p. 40).

\section{Aplicabilidade da lei}

Entende-se que o estudo da Lei de Anistia é fundamental para que se realize uma visitação à memória histórica recente do país, pois essa é "uma conquista, é também um instrumento e um objeto de poder" (LE GOFF, 2003, p. 470), vez que o último período viveu-se sob regime de exceção podendo remeter a muitos questionamentos.

No campo jurídico mantiveram-se muitas normas e leis oriundas dessa época. $\mathrm{O}$ estudo da referida lei, se justifica, uma vez que ela se mantém viva comprovando-se, através da elaboração das Leis 9.140/1995 e 10.559/2002. Tal polêmica deu origem a matéria, onde o parágrafo $2^{\circ}$ do artigo $1^{\circ}$ da Lei da Anistia diz: “Excetuam-se dos benefícios da anistia os que foram condenados pela prática de crimes de terrorismo, assalto, sequestro e atentado pessoal" (Lei $\left.n^{\circ} 6.683 / 79\right)$.

Posteriormente, tal assunto foi tratado, através de atos das disposições constitucionais transitórias, bem como, leis posteriores, decretos, regulamentos e portarias, que aperfeiçoaram e especificaram as regras para a concessão de anistia a civis e militares, garantindo direitos aos anistiados e seus familiares.

Cabe ressaltar que além da Lei 6.683/79, houve outras legislações que trataram da anistia. Abaixo a legislação brasileira sobre esse assunto:

1. Art. $8^{\circ}$ do Ato das Disposições Constitucionais Transitórias da Constituição Federal de 1988 (concede anistia);

2. Lei 10.559/02: Regulamenta o art. $8^{\circ}$ do Ato das Disposições Constitucionais Transitórias;

3. Portaria 893/MJ/04: Aprova o regimento interno da Comissão de Anistia;

4. Decreto 4.897/03: Regulamenta o parágrafo único do art. $9^{\circ}$ da Lei 10.559/02; 
5. Portaria Normativa 657/MD/03: Estabelece normas para execução, no âmbito do Ministério da Defesa e das Forças Armadas, do parágrafo único do art. 18 da Lei 10.559/02;

6. Lei $\mathrm{n}^{\mathrm{0}}$ 6.880, de 9 de dezembro de 1980: Dispõe sobre o Estatuto dos Militares;

7. Decreto 84.143/79: Regulamenta a Lei $6.683 / 79$, que concede anistia e dá outras providências;

8. Parecer AGU/JD-1/2003/03: Aprovado em 21 de outubro de 2003, trata do militar anistiado e sua promoção, bem como de aspectos da Lei 10.559/02 (inovação em relação ao art. $8^{\circ}$ do Ato das Disposições Constitucionais Transitórias).

Dessa forma, através das medidas contitucionais promulgadas, objetivou-se a consolidação e a manutenção da anistia de perseguidos e perseguidores políticos.

Aspectos e relevâncias

Diferentemente do ocorrido em outros Países da América do Sul, o combate ao totalitarismo e as ditaduras militares teve um desfecho diferente até, então, no Brasil.

A dinâmica político-social parece viver de ciclos contagiantes. Dessa forma, após a segunda guerra mundial começou a nascer uma leitura nacionalista que levou boa parte dos países da América do Sul a ter ditaduras militares, com grande concentração de poder. Percebe-se que Chile, Argentina, Paraguai e Brasil viveram situações parecidas mesmo que o tratamento dado ao final tenha sido diferenciado.

No Brasil pós-governo João Batista Figueiredo, último General Presidente, ele conseguiu sancionar uma lei que combinou uma distinção lenta, gradual e progressiva observada na Lei de Anistia.

As sessões públicas têm sido realizadas na contracorrente da postura de uma parcela da sociedade brasileira, que entende o debate sobre a anistia política como um tema ultrapassado e que se pretendia na verdade era salvaguardar e legitimar os atos praticados no uso do poder unilateral à frente do Estado Brasileiro por entender que a Lei de Anistia foi formulada de maneira a perdoar agressores e vítimas de forma que os últimos se dessem por satisfeitos em readquirir direitos políticos, enquanto que os ditadores, ou seja, os torturadores ficassem sem pagar pelos atos praticados em defesa da continuidade de ações antidemocráticas (CASTRO, s/d). 
Ultimamente tem se falado na revisão da Lei de Anistia, e um conselho foi criado pelo Presidente Lula com objetivo de resgatar um passado obscuro e cruel, onde várias pessoas perderam a vida ou foram torturadas (GONÇALVES, 2008).

A análise dos fatos ocorridos com a apresentação de um discurso com quase nenhum conhecimento da população brasileira faz desencadear uma linha de pensamento voltada para a reflexão, para que se possa situar no tempo e no espaço político, vislumbrando como será o futuro. A liberdade de pensamento e expressão não pode ser tolhidas de forma retrógrada, nem perderem de vista seus princípios norteadores, partindo do pressuposto que uma democracia deve ser vista com segurança e confiança deixando de lado aqueles rebuscados sentimentos conflitantes entre o presente e o passado ( GONÇALVES, 2008).

A lei de Anistia deve ser em análise utilizada para levantar a verdade dos fatos ocorridos de forma que conhecendo o passado, se possa no presente, fazer revisão de leis para assegurar no futuro os plenos direitos democráticos.

\section{Redemocratização brasileira}

Discutiremos a seguir a redemocratização no âmbito de seu conceito e história e a seguir a anistia política e redemocratização após 1964.

\section{Conceito e História}

O processo de redemocratização que ocorreu no País entre meados dos anos 70 e 1984 foi o resultado de um profundo processo político. Nesse contexto histórico, a palavra democracia tem sua origem na Grécia Antiga. "Demo" significa povo e "kracia" significa governo. O Preâmbulo da Constituição da República Federativa do Brasil de 1988, assim menciona a instituição de um Estado Democrático:

Nós, representantes do povo brasileiro, reunidos em Assembleia Nacional Constituinte para instituir um Estado Democrático, destinado a assegurar o exercício dos direitos sociais e individuais, a liberdade, a segurança, o bemestar, o desenvolvimento, a igualdade e a justiça como valores supremos de uma sociedade fraterna, pluralista e sem preconceitos, fundada na harmonia social e comprometida, na ordem interna e internacional, com a solução pacífica das controvérsias, promulgamos, sob a proteção de Deus, a seguinte Constituição da República Federativa do Brasil. (CONSTITUIÇÃO DE 88). 
Quanto à Redemocratização tem sido objeto de estudos de muitos pesquisadores ao longo dos anos e é vista como o processo de restauração da democracia e do estado de direito em países ou regiões que passaram por um período de autoritarismo ou ditadura. No Brasil, foram dois processos de transição política que acabaram com regimes ditatoriais. A primeira redemocratização ocorreu em 1945, com o fim do Estado Novo (1937-45), golpe militar implantado pelo governo de Getúlio Vargas. A segunda transição aconteceu em 1985, com o fim do Regime Militar (1964-85). O final do governo militar de 1964, culminou com a hiperinflação e, em maio de 1985, o Congresso Nacional aprovou a emenda constitucional que acabava com os últimos vestígios da ditadura (SILVA, 2010).

Neste contexto, onde, a luta foi grande para que houvesse uma transição do regime de exceção para democracia de forma pacífica, apresentaram-se várias personalidades públicas associadas a milhões de brasileiros que organizaram $o$ movimento: "Diretas Já", sendo desta forma, o primeiro passo e a esperança de um povo cansado de não ter voz sentir que mudanças viriam pela frente, uma vez que em apoio à Emenda Constitucional que propunha eleições livres e diretas para a presidência da República, mesmo não passando naquele momento, abriu grandes possibilidades que se confirmou com a promulgação da Constituição de 1988 (SILVA, 2010).

Ao buscar pelo direito à verdade promoveu-se a elaboração de diversos relatórios acerca das desaparições e torturas realizadas pelo regime militar brasileiro.

No Brasil, o trabalho feito pela Comissão Nacional da Verdade, conseguiu divulgar o conjunto de violações cometidas pelo Estado. O Relatório Final tem o intuito de revelar, esclarecer e reconhecer oficialmente os abusos e violações cometidos até 1985, indicando responsabilidades institucionais e recomendando reformas legais. Desta forma, o presidente da Comissão de Anistia do Ministério da Justiça, informou em seus relatos que a luta pela verdade e pela memória também devem vir acompanhadas das dimensões da justiça e da reparação (KALLÁS, 2015).

\section{Anistia e a crise política no Brasil após 1964}

O Brasil pôde-se dizer que viveu por vinte e um anos sob as rédeas de um regime ditatorial. O ano de 1964 ficou marcado na história do Brasil pelo golpe militar que derrubou o presidente eleito pelo voto popular, João Goulart, colocando em seu lugar à frente do Governo brasileiro uma junta militar. Esse regime perdurou de 1964 a 1985 e caracterizou-se pela supressão dos direitos individuais e políticos, pela censura e pela perseguição e repressão aos que eram contrários ao regime militar.

O trecho abaixo citado por Rezende torna explicito os interesses dos militares. 
A afirmativa de que a ditadura tentava legitimar suas ações e medidas através da construção de um suposto ideário de democracia significa que se está empregando o sentido de legitimidade como busca de reconhecimento, por parte da maioria dos segmentos sociais, em torno dos valores propalados como fundantes do regime militar, bem como a procura de adesão às suas pressuposições em torno da convivência social (REZENDE, 2001, p. 3).

Ainda de acordo com o autor, ao passar para a sociedade o ideário de um governo democrático, os militares ganhavam apoio popular. Assim, tornava-se necessário por parte do governo manter o domínio sobre os meios de comunicação de massa, usando-os ao seu favor para propagar a suposta democracia.

Com o propósito de calar a voz dos que criticavam o governo, “a repressão procurou silenciar as vozes que pediam democracia e liberdade, como grupos de teatro, músicos e organizações de esquerda e estudantil" (GASPARI, 2002, p. 211). No final deste regime de exceção, o país já apresentava desgastes de toda a ordem, notadamente a inflação e a recessão econômica, oportunizando que as vozes da oposição ganhassem terreno com o surgimento de novas agremiações partidárias e o fortalecimento dos sindicatos. A sociedade brasileira viu-se tolhida de seus direitos constitucionais, civis e políticos e enfrentou o rigoroso controle das forças militares.

A partir de 1985, por meio da liberalização política do regime e do fortalecimento da sociedade civil, o país vivenciou um processo de democratização, o qual teve o seu ápice com a promulgação da "Constituição Cidadã", a Constituição de 1988. O texto constitucional brasileiro de 1988 desenhou um novo pacto político e social e instaurou o regime democrático no país. Além disso, a Constituição representou um grande avanço em relação aos direitos e garantias fundamentais, uma vez que prestou aos direitos humanos importante ênfase, permitindo outro olhar e assegurando ao povo brasileiro a liberdade tanto sonhada (CASTRO, s/d).

\section{A redemocratização brasileira e sua importância para o ensino da história}

Apresentamos um breve histórico das transformações ocorridas no ensino de História durante o Regime Militar no Brasil. Neste contexto percebe-se que a escola foi usada como reprodutora dos ideais militares no âmbito educacional.

As discussões acerca das transformações ocorridas no ensino da história durante o Regime Militar no Brasil ocupa grande destaque no cenário historiográfico. Dentre os fatores responsáveis pelas mudanças, a intervenção do Estado na educação destaca-se como elemento importante para manter a política de dominação própria de tal governo 
militar, uma vez que a escola e a universidade desempenham a função de reprodutoras das ideologias do mesmo.

Caracterizando o ensino da história que pode ser entendido a partir das décadas de 30 e 40 deste século, onde orientado por uma política nacionalista e desenvolvimentista, o Estado, também passou a realizar uma intervenção mais normativa na educação e foram criadas as faculdades de filosofia no Brasil, formando pesquisadores e professores, consolidando-se uma produção de conhecimento científico e cultural mais autônoma no país. (PCNs, 1998, p. 19).

Nesta perspectiva, o Estado brasileiro sempre se mostrou preocupado com a forma com que o conhecimento construído com o estudo das Ciências Humanas, em especial com o conhecimento histórico era passado à sociedade. Por tal motivo, foram realizadas as reformas no ensino da história, uma vez que esta significava ameaça aos interesses do Estado representado pelos militares. Esvaziar o teor crítico da disciplina era a garantia da segurança nacional, diante das transformações sociais ao longo do período ditatorial.

No Brasil, vive-se um período de redemocratização com o fim da Era Vargas. Nesse momento, de acordo com os PCNs (1998, p. 23-24) “a História passou a ser novamente objeto de debates quanto às suas finalidades e relevância na formação política dos alunos". Portanto, era preciso modernizar as práticas de ensino, reformular os conteúdos, atendendo aos novos desafios da sociedade brasileira, sobretudo na área do desenvolvimento tecnológico, deixados pelo governo Vargas com o investimento na valorização cultural e no processo de industrialização com o crescimento dos meios de comunicação de massa.

No decurso, três anos após as novas propostas educacionais realizadas com a LDB em 1961 tiveram distantes da prática com o golpe de estado ou revolução de 1964 como se referem alguns historiadores, para denominar a derrubada do governo de João Goulart em 1964. Preocupados com a formação política dos cidadãos brasileiros, o governo militar logo cria as reformas no sistema educacional, adequando-as a uma proposta pedagógica voltada para os interesses do Estado, tornando as universidades e escolas em propagadoras de suas ideologias. Segundo Fonseca (1993, p. 19), “O papel da educação assim como as metas para o setor, estabelecidas pelo Estado Brasileiro a partir de 64, estiveram estritamente vinculados ao ideário de segurança nacional e de desenvolvimento econômico".

Para complementar esta medida, vieram às reformas curriculares, onde as disciplinas de História e Geografia foram substituídas pelos Estudos Sociais, levando ao esvaziamento dos conteúdos, fazendo-os regredir ao método mnemônico, fazendo o aluno decorar datas, nomes e fatos importantes da história com vistas ao desenvolvimento do nacionalismo, elemento importante na formação do indivíduo para a efetiva manutenção 
do regime instituído (BRASIL/SEF, 1997, p. 25-26). Daí surge a necessidade de reformular os currículos, moldando-os aos interesses da classe dominante.

Neste contexto, as leis regulamentares 4.024/68 e a 5692/71 foram modificadas em sua essência. A inspiração liberalista cede lugar a tecnicista que deixa de lado a preocupação com o conteúdo, privilegiando o método adotado no desenvolvimento dos conteúdos escolares selecionados. Essas mudanças na forma de se conceber o ensino, dá a educação dinamismo nas técnicas, das mais variadas formas, seja nas propostas pedagógicas ou nas formas de organização do sistema escolar, bem como o parcelamento do trabalho pedagógico com a sua hierarquização, essa nova forma de pensar a educação dá maior possibilidade de controle sobre a escola e a universidade (KALLÁS, 2015).

Isso mostra que os ideais do governo era reprimir o conhecimento histórico, temendo as consequências que este poderia trazer, sobretudo, por em risco o domínio que mantinha sobre a população brasileira. Por isso os conflitos políticos e mazelas sociais eram abafados, retirados dos livros didáticos.

Ao fim da ditadura e de um breve período de ajustes da democracia nascente, as reformas neoliberais da educação nos anos 1990, durante a presidência de Fernando Henrique Cardoso, ditam o novo modelo que hoje informa os cursos de formação de professores, com todas as suas contradições e problemas, ademais de alguns méritos.

Para KALLÁS (2015), deve-se considerar que as temáticas da História do Tempo Presente devem receber maior destaque nas diretrizes curriculares do ensino da história, tendo em vista a possibilidade de uma melhor compreensão pelos alunos de permanências e/ ou continuidades no processo histórico. Segundo a autora, ao partir de temas que o aluno vivencia em seu cotidiano, deve-se analisar os acontecimentos com profundidade histórica, integrando-os numa perspectiva de processo. A aprendizagem e a produção de conhecimento em sala de aula podem tornar-se significativas. Essa perspectiva de construção do conhecimento tem a intenção de estimular a reflexão sobre temas atuais sem, cair no imediatismo tão recorrente entre as novas gerações.

Todavia, a autora ainda acrescenta que:

A discussão sobre o que foi e como se sucederam as práticas repressivas naquele período trazem para o debate as denúncias dos crimes cometidos pelo Estado, a publicitação das reivindicações dos familiares de mortos e desaparecidos, a luta pela reparação das injustiças, os avanços obtidos com relação à justiça de transição e, por fim, a incompletude desse processo. Nessa etapa, torna-se importante trazer para a sala de aula a importância das políticas de memória, os resultados produzidos pelas Comissões da Verdade e de Anistia, bem como o estado da arte das discussões sobre reparação, que para além de econômicas, devem possibilitar a disputa de hegemonia em torno da memória da ditadura militar (KALLÁS, 2015, p.10). 
Dessa forma, a dificuldade de estimular a aprendizagem da história pode ser explicada através da própria história e dos desafios estabelecidos pela ditadura na restrição do conhecimento.

\section{Considerações finais}

O presente artigo é resultado da pesquisa - Processo de Redemocratização do Brasil após 1964 com ênfase na Lei de Anistia, onde se apresentou os conceitos da Lei $n^{\circ}$ $6.683 / 79$, redemocratização brasileira e buscou fazer uma análise a respeito da eficácia da Lei de Anistia, bem como sua importância para o ensino da história.

A Lei da Anistia foi o ato legislativo mais importante e que marcou o fim da ditadura militar no Brasil. Não obstante, esta não poderá ser vista com revanchismo, e sim, como forma de fazer justiça àqueles que foram perseguidos, humilhados e torturados por forças ditatoriais que imaginavam ser a palmatória do mundo sem nunca aceitar o contraditório que fundamenta o pensamento de não concordar com a tese em questão, mas que essa tese possa ser defendida tantas vezes que se achar necessário. $O$ aspecto positivo é o reconhecimento do Estado quanto ao direito de resistir ao regime autoritário e o consequente direito à reparação.

A reivindicação pelo direito ao acesso aos arquivos dos centros de repressão da ditadura militar e, mais recentemente, quanto às reações contrárias ao processo de criação de uma Comissão de Verdade avaliou-se que é fundamental para uma efetiva investigação e análise dos casos para que na forma da lei seja feito a justiça muito aguardada por todos.

Ao analisar a aplicabilidade da lei percebe-se o direito à reparação no Brasil, dando ênfase a declaração de anistiado é um gesto oficial e legal de pedidos de desculpas pelo Estado em que reconhece que perseguiu politicamente a um cidadão ou uma cidadã e que promoveu contra eles atos de exceção, causando-lhe prejuízos morais e materiais a serem reparados.

É relevante a análise dos fatos ocorridos com a apresentação de um discurso com quase nenhum conhecimento da população brasileira, onde faz-nos desencadear uma linha de pensamento voltado para a reflexão, no sentido de nos situar no tempo e no espaço político e como será o futuro.

O processo de redemocratização que ocorreu no país entre meados dos anos 70 e 1984 e a tomada de conhecimento da luta para que houvesse uma transição do regime de exceção para democracia de forma pacífica foram estudos de muitos pesquisadores ao longo dos anos. $\mathrm{O}$ fato de estar-se no começo como democracia não se liberta do dever e da responsabilidade de se construir um país mais humano, sem preconceitos, sejam eles de quaisquer origens. 
As discussões acerca das transformações ocorridas no ensino da história durante o Regime Militar no Brasil foi motivo de destaque no cenário historiográfico.

A análise sobre o que foi e como se sucederam as práticas repressivas naquele período trazem para o debate as denúncias dos crimes cometidos pelo Estado. Nesse contexto, torna-se relevante trazer para a sala de aula a importância das políticas de memória, os resultados produzidos pelas Comissões da Verdade e de Anistia.

Este tema além de ser muito amplo é também muito complexo, ficando muito a ser explorado. No Brasil as mudanças com certeza virão e falar de uma Justiça e processo de democracia efetiva é um tema que muito teremos de estar em constante debate por ser uma experiência de recriação permanente e também, pela velocidade com que os fatos ocorrem.

\section{Referências}

BRASIL. Lei $\mathrm{n}^{\circ}$ 6.683, de 28 de agosto de 1979. Concede anistia e dá outras providências. Diário Oficial da União [da] Republica Federativa do Brasil, Brasília-DF, 28 ago. 1979. Disponível em: <www.planalto.gov.br/ccivil_03/Leis/L6683.htm>. Acesso em 20 set. 2013, e <http://www2.camara.leg.br/legin/fed/lei/1970-1979/lei-6683-28-agosto-1979-366522norma-pl.html> . Acesso em 09 abr. 2017.

BRASIL. Lei $n^{\circ}$ 9.140, de 04 de dezembro de 1995. Reconhece como mortas pessoas desaparecidas em razão de participação, ou acusação de participação, em atividades políticas, no período de 2 de setembro de 1961 a 15 de agosto de 1979, e dá outras providências. Diário Oficial da União [da] República Federativa do Brasil, Brasília-DF, 5 dez. 1995. Disponível em:<http://www2.camara.leg.br/legin/fed/lei/1995/lei-9140-4-dezembro-1995348760-normaatualizada-pl.html>. Acesso em 10 abr. 2017.

BRASIL. Ministério da Educação e Cultura, Secretaria de Educação Fundamental. Parâmetros Curriculares Nacionais (PCN): História. Brasília. MEC/SEF, 1998.

BRASIL. Constituição (1988). Constituição da República Federativa do Brasil: promulgada em 5 de outubro de 1988. 44 ed. São Paulo: Saraiva, 2010. 1.000 p. (Coleção Saraiva de Legislação).

CASTRO, Leonardo. O regime militar de 1964. S/D. Disponível em <http://novahistorianet.blogspot.com.br/2009/01/o-regime-militar-de-1964.html>. Acesso em 13 abr. 2017.

COMISSÃO NACIONAL DA VERDADE. Relatório Final. Brasília: CNV, 2014.

CUNHA, Paulo Ribeiro da. Militares e anistia no Brasil: um dueto desarmônico. In: TELES, Edson e SAFATLE, Vladimir (Orgs.). O que resta da ditadura: a exceção brasileira. São Paulo: Boitempo, 2010, p. 15 -40. 
FONSECA, Selva Guimarães. Caminhos da História ensinada. Campinas: Papirus, 1993.

GASPARI, Elio. A ditadura envergonhada. São Paulo: Companhia das Letras, 2002.

GONCALVES, D. N. Os Processos de Anistia Política no Brasil: Do Perdão à “Reparação" p. 38 - 48, Revista de Ciências Sociais, v. 39, n. 1, 2008.

KALLÁS, Ana Lima. Ditadura e redemocratização do Ensino de História: revisitação a partir de eventos recentes. XXVIII Simpósio Nacional de História - lugares dos historiadores: velhos e novos desafios. De 27 a 31 de julho de 2015, Florianópolis-SC, Pág. 10.

LE GOFF, Jacques. História e Memória. Campinas: UNICAMP, 2003.

MEZAROBBA, Glenda. Um Acerto de Contas com o Futuro - a anistia e suas conseqüências: um estudo do caso brasileiro. São Paulo: Associação Editorial Humanitas; FAPESP, 2006.

POVO. AGU diz ao Supremo que Lei da Anistia impede punição a torturadores. 02/02/2009.

REZENDE, M. J. A ditadura militar no Brasil: repressão e pretensão de legitimidade 19641984. Londrina: UEL, 2001.

SILVA, Tiago Ferreira da. Lei de Anistia. 2010. Disponível em: <http://www.infoescola.com/historia-do-brasil/lei-da-anistia/>. Acesso em 11 abr. 2017.

SILVA, Tiago Ferreira da. Redemocratização do Brasil. Disponível em:

<http://www.historiabrasileira.com/brasil-republica/redemocratizacao-do-brasil>. Acesso em 15 abr. 2017. 